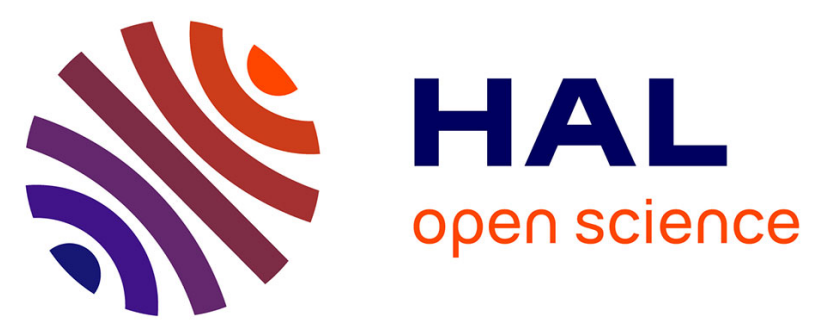

\title{
Analysis of the middle atmospheric ozone using SABER observations: a study over mid-latitudes in the northern and southern hemispheres
}

Vaidehi Joshi, Som Sharma, Kondapalli Niranjan Kumard, Nisha B Patel, Prashant Kumar, Hassan Bencherif, Priyanka Ghosh, Chintan Jethva, Rajesh Vaishnav

\section{To cite this version:}

Vaidehi Joshi, Som Sharma, Kondapalli Niranjan Kumard, Nisha B Patel, Prashant Kumar, et al.. Analysis of the middle atmospheric ozone using SABER observations: a study over mid-latitudes in the northern and southern hemispheres. Climate Dynamics, 2020, 10.1007/s00382-020-05124-6 . hal-02455982

\author{
HAL Id: hal-02455982 \\ https://hal.univ-reunion.fr/hal-02455982
}

Submitted on 27 Jan 2020

HAL is a multi-disciplinary open access archive for the deposit and dissemination of scientific research documents, whether they are published or not. The documents may come from teaching and research institutions in France or abroad, or from public or private research centers.
L'archive ouverte pluridisciplinaire HAL, est destinée au dépôt et à la diffusion de documents scientifiques de niveau recherche, publiés ou non, émanant des établissements d'enseignement et de recherche français ou étrangers, des laboratoires publics ou privés. 


\title{
Analysis of the middle atmospheric ozone using SABER observations: a study over mid-latitudes in the northern and southern hemispheres
}

\author{
Vaidehi Joshi ${ }^{1}$. Som Sharma ${ }^{1}\left[\right.$ ] Kondapalli Niranjan Kumar ${ }^{1} \cdot$ Nisha Patel $^{2} \cdot$ Prashant Kumar $^{3} \cdot$ Hassan Bencherif ${ }^{4}$. \\ Priyanka Ghosh ${ }^{1}$. Chintan Jethva ${ }^{5} \cdot$ Rajesh Vaishnav $^{6}$
}

\begin{abstract}
The present study focuses on the middle atmospheric ozone variability using 14 (2002-2015) years of Sounding of the Atmosphere using Broadband Emission Radiometry onboard Thermosphere Ionosphere Mesosphere Energetics and Dynam-ics satellite observations over the mid-latitude regions of northern and southern hemispheres. It is noted that ozone buildup starts late winter, and peaks during the springtime and gradually decreases in summer to autumn transitional period in both the hemispheres. The time series of ozone indicates the dominant annual and semi-annual oscillations in the middle atmos-phere. The annual oscillation $(\mathrm{AO})$ is found to be dominant over both the hemispheres, while the semiannual oscillation (SAO) peaks at two different altitude regions: $30-60 \mathrm{~km}$ and $80-100 \mathrm{~km}$. Further, the amplitude of AO is much significant than SSAO and MSAO. It is also noted another significant oscillation that peaks at $\sim 4$ months in the altitude range $60-80 \mathrm{~km}$. The strength of these oscillations at different sites is studied by comparing it with the zonal mean spectrum to assess the longitudinal asymmetry. It is found that the longitudinal asymmetry is more significant in the northern hemisphere than the southern hemisphere. This can be attributed to the differences in the land (elevated topographies in the northern hemisphere) and primarily ocean (in southern hemisphere) contrast that further contributes to the differences in the strength of the verti-cally propagating planetary-scale waves modulating the middle atmospheric ozone.
\end{abstract}

Keywords Middle atmosphere $\cdot$ Ozone $\cdot$ SABER $\cdot$ Atmospheric oscillations

\section{Introduction}

Electronic supplementary material The online version of this article (https://doi.org/10.1007/s00382-020-05124-6) contains supplementary material, which is available to authorized users.

Som Sharma

somkumar@prl.res.in

Kondapalli Niranjan Kumar niranjankondapalli@yahoo.com

1 Physical Research Laboratory, Ahmedabad, India

2 Kadi Sarva Vishwavidyalaya, Gandhingar, Gujarat, India

3 Atmospheric and Oceanic Sciences Group, Space Applications Centre, Ahmedabad, India

4 Université de La Réunion, LACy, UMR 8105, Saint Denis, Reunion Island, France

5 Physics Department, Saurashtra University, Rajkot, India

6 Institut für Meteorologie, University of Leipzig, Leipzig, Germany
The middle atmosphere is a region, which interacts with the climate system of the lower atmosphere and the richly ionised upper atmosphere. The middle atmospheric ozone has been a subject of the most significant scientific research to the global scientific community over the past few decades (Hingane 1984; Fioletov and Shepherd 2003; Remsberg and Lingenfelser 2010; Steinbrecht et al. 2004; Rieder et al. 2013; Mze et al. 2010; Sivakumar et al. 2007; Allen et al. 1984). For instance, Remsberg and Lingenfelser (2010) studied the decadal-scale ozone variations in the upper stratosphere due to dynamical forcing over the northern mid-latitude. In particular, the stratospheric ozone is more significant as it absorbs ultraviolet radiation and is also more sensitive to the anthropogenic activities, chemical reactions and atmospheric dynamics (Portmann et al. 2012; Cicerone 1987; Solomon et al. 1996; Brasseur and Hitchman 1988). For example, the ozone variations are significantly modified due to the chemical reactions such as the chlorine and 
bromine chemistry (Garcia and Solomon 1994). Solomon et al. (1998) studied that the temperature fluctuations gave major contributions to mid-latitude ozone depletion due to heterogeneous chlorine activation on liquid sulfate aerosols at temperature near $200-210 \mathrm{~K}$, particularly after major volcanic eruption. Nevertheless, the seasonal variations of ozone have a great deal of repeatability from year to year which occurs in most of the middle atmosphere in the extratropical latitudes (Thomas 1990).

The seasonal climatology of the middle atmospheric ozone is reported in a number of previous studies from different space-borne and ground-based observations. Fioletov and Shepherd (2003) studied ozone anomalies over the Northern and the Southern hemispheric mid-latitudes, which reveals wintertime ozone rising continuously with photochemical decay until the end of autumn and then it swiftly erased once the next winter's build-up begins. Perliski et al. (1989), studied the monthly variations of ozone mixing ratio computed by the two-dimensional photochemical model and compared with SBUV observations in the middle atmosphere at high latitudes. Their results show that modeled ozone abundances increase in the winter due to transport and decrease in the summer due to chemical destruction. Perliski and London (1989) studied ozone mixing ratio data using nine years (October 1978-September 1987) of Nimbus-7 SBUV satellite to analyse the vertical and seasonal distribution of the zonal ozone variations. It is shown that zonal wavenumber 1 is larger during winter than summer. Frederick et al. (1983) studied the global distribution of stratospheric ozone derived from Nimbus 4 and 7 satellites for the period June 1970 through May 1972 and 1978-1979. Their study revealed maximum ozone mixing ratio develops in autumn and persists through the winter season in the upper stratosphere. Schneider et al. (2005) studied ozone mixing ratio (OMR) using ground-based instrument (Bordeaux microwave radiometer) between 1995 and 2002 in the middle atmosphere which shows seasonal ozone variations mainly appear as an annual cycle in the middle and upper stratosphere and a semi-annual cycle in the mesosphere with amplitude and phase depending on altitude.

The El Nino/Southern Oscillation strongly influence ozone in both northern and southern mid-latitudes, especially during spring and towards low latitudes (Rieder et al. 2013). Long-term variability of middle atmospheric ozone and its response towards oscillations has been studied by Nath and Sridharan (2014), where they found semi-annual oscillation (SAO) is predominant in the lower stratosphere and upper mesosphere. Nagahama et al. (1999) reported Annual and semi-annual variations at 50 and $76 \mathrm{~km}$, respectively, in the ozone mixing ratio using ground-based observations. Perliski et al. (1989) reported the annual ozone variation is largely due to the annual variation in the oddoxygen production rate, and in the upper stratosphere, the computed annual ozone variation is caused by the large calculated annual oscillation in temperature. Perliski and London (1989) analyse the distributions of the long-term average annual and semi-annual ozone oscillations in the lower, middle, and upper stratosphere over the high latitudes of both the hemispheres $\left(65^{\circ} \mathrm{S}-65^{\circ} \mathrm{N}\right)$. Their study shows year-to-year changes of amplitudes of the annual and semiannual variations are generally small except in the tropical mid-stratosphere and the southern subpolar upper stratosphere. Furthermore, solar events affect the middle atmospheric ozone significantly. Marsh et al. (2002) presented the dynamical structure of distributed ozone which indicates that the vertical advection of atomic oxygen by the solar diurnal tides plays an important role in determining ozone concentration. Ozone response to the solar variability is positive in the lower thermosphere for higher latitudes (Huang et al. 2016). Beig et al. (2012) investigated the effects of decadal solar variability on ozone using HALOE satellite and HAMMONIA model data, from which they observed that the annual-mean solar signal in ozone is found to be insignificant in the lower mesosphere, whereas it is of the order of 5\%/100 $s f u$ in the upper mesosphere for mid-latitudes.

Many of the above studies indicated that there is a significant spatial and temporal heterogeneity in the ozone distribution globally. While the middle atmospheric ozone is also modulated by the various forcing from above and below the middle atmosphere. For instance, as discussed in the above studies the solar input significantly modulates the middle atmospheric ozone (Marsh et al. 2002). Further, the concentration of ozone over the northern hemisphere $(\mathrm{NH})$ and southern hemisphere ( $\mathrm{SH}$ ) is very interesting to understand for their diverse properties. In addition, the latitudinal and longitudinal coupling is another relevant aspect for a better understanding of atmospheric system over both the hemispheres. Therefore, the objective of our study focused on the seasonal and interannual variability of middle atmospheric ozone using the longer time series data as the previous studies use the limited temporal data. We have used ozone data from the Sounding of the Atmosphere using Broadband Emission Radiometry (SABER) instrument (Russell et al. 1999) on-board Thermosphere-Ionosphere-MesosphereEnergetics and Dynamics (TIMED) satellite for the time period January 2002-December 2015 from the altitude range of $20-100 \mathrm{~km}$ over Site $1\left(50^{\circ} \mathrm{N}, 120^{\circ} \mathrm{W}\right)$, Site $3\left(50^{\circ} \mathrm{N}\right.$, $\left.2.5^{\circ} \mathrm{E}\right)$ and Site $5\left(50^{\circ} \mathrm{N}, 120^{\circ} \mathrm{E}\right)$ in the $\mathrm{NH}$, and over Site $2\left(50^{\circ} \mathrm{S}, 120^{\circ} \mathrm{W}\right)$, Site $4\left(50^{\circ} \mathrm{S}, 2.5^{\circ} \mathrm{E}\right)$ and Site $6\left(50^{\circ}\right.$ $\mathrm{S}, 120^{\circ} \mathrm{E}$ ) in the $\mathrm{SH}$. The similarities, differences, longterm variabilities, oscillations and seasonal variations in the ozone mixing ratio (OMR), have been extensively analysed. 


\section{Data and methodology}

\subsection{SABER/TIMED observations}

In the present work, we used data from the SABER instrument, one of the four instruments onboard NASA's TIMED satellite launched on December 7, 2001. The SABER/ TIMED has provided day and night time ozone measurements on a daily basis in the middle to upper atmosphere $(15-105 \mathrm{~km})$ since 2002. It is a multi-channel radiometer designed to measure heat emitted by the atmosphere over a broad altitude and spectral range $(1.27-16.9 \mu \mathrm{m})$ in the limb direction. The primary goal of the SABER instrument is to deliver the data required to enhance the understanding of the fundamental processes, chemistry variations of key gases in the oxygen and hydrogen families and the movement of air, or dynamics, between atmospheric regions at lower to higher altitudes, pole to equator, and east-west directions. It measures the vertical distributions of elemental constituents, such as ozone, water vapour, carbon dioxide, and nitrogen and hydrogen gases, as well as temperature. It obtains vertical profiles with $2 \mathrm{~km}$ altitude resolution. Over the course of one orbit, SABER observes both the hemispheres $\left(52.5^{\circ}\right.$ $\mathrm{N}-52.5^{\circ} \mathrm{S}$ ). It orbits 15 times per day at nearly $625 \mathrm{~km}$ altitude with an orbital inclination of $74.1^{\circ}$ to the equator. SABER observes ozone emission in a band-pass from 1010 to $1150 \mathrm{~cm}^{-1}(9.9-8.7 \mu \mathrm{m})$ and it autonomously retrieved from two separate channels: $9.6 \mu \mathrm{m}$ and $1.27 \mu \mathrm{m}$. SABER O3 measurements have a precision of $\sim 2 \%$ between the altitudes range of $10-65 \mathrm{~km}$ and $\sim 5 \%$ in the mesosphere (Russell et al. 1999).

\subsection{Study area}

In the present study, six sites are selected in the $\mathrm{NH}$ and $\mathrm{SH}$. Figure 1 shows the pictorial view of the study sites. $\mathrm{NH}$ consists of $\sim 68 \%$ landmass and it consists of all of Europe, North America, and Asia, etc. Here, Sites 1, 3 and 5 in NH have the same latitude $50^{\circ} \mathrm{N}$, which is a region between the Tropic of Cancer $\left(\sim 23.5^{\circ} \mathrm{N}\right)$ and the Arctic Circle $\left(66.5^{\circ} \mathrm{N}\right)$, known as the North Temperate Zone. Further, the SH consists of very low landmass $\sim 32 \%$ and its geography shows that it has mostly oceans/seas. South Pacific, South Atlantic, and Indian Oceans are in the SH, where only few percent lands are there covering South America, one-third of Africa and all of Australia. Sites 2, 4 and 6 in SH also have the same latitude $50^{\circ} \mathrm{S}$ which is the region between the Tropic of Capricorn $\left(\sim 23.5^{\circ} \mathrm{S}\right)$ and the Antarctic Circle $\left(66.5^{\circ}\right.$ S), known as the South Temperate Zone. As we know the importance of both the hemispheres, we have done a comprehensive study to further understand middle atmospheric ozone variability in the different hemispheres. We have used $5^{\circ} \times 15^{\circ}$ latitude-longitude grids centered on the study Sites.

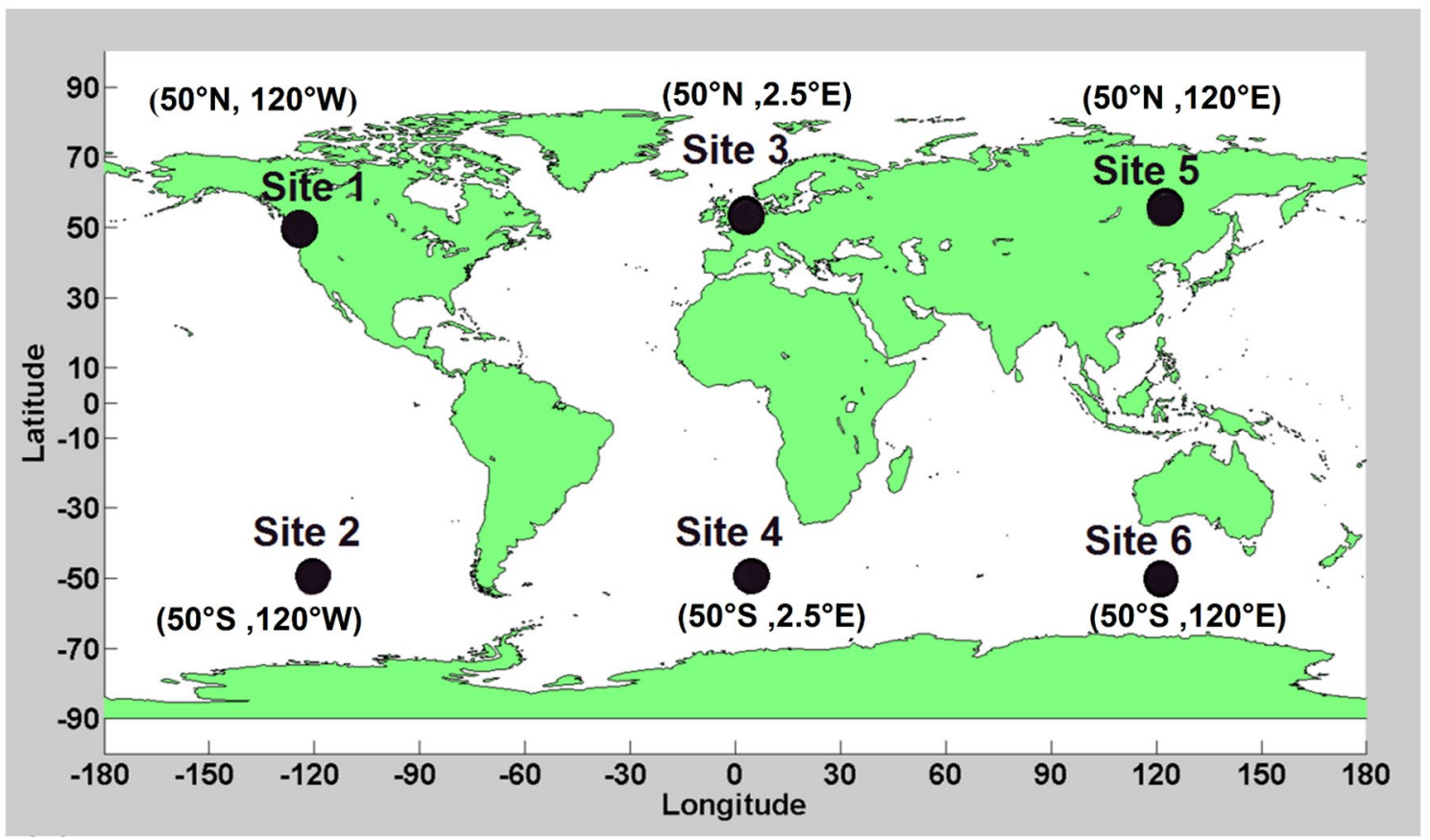

Fig. 1 The geographical map indicating the six sites over the NH and the SH chosen for this work. The locations of the selected sites are shown in a "solid black circle" 


\subsection{Lomb scargle periodogram (LSP) and wavelet transform analysis}

The Lomb-Scargle periodogram (LSP) is a common tool in the frequency analysis of unequally spaced data equivalent to the least-squares fitting of sine waves (Zechmeister and Kürster 2009). A periodogram calculates the significance of different frequencies in time-series data to identify any intrinsic periodic signals. It is similar to the Fourier transform but is optimized for unevenly time-sampled data and for different waveforms in periodic signals. Thus, the LSP is a very useful technique to determine frequency components in time-series data. LSP is applied to determine the actual periods of the SAO and AO. In addition to this, we also applied a Morlet wavelet analysis. The Morlet wavelet is the most common function used in astrophysical signal expansions (Katsavrias et al. 2012). Furthermore, due to its Gaussian support, the Morlet wavelet expansion inherits optimality as regards the uncertainty principle (Morlet et al. 1982). It can be preferable for the analysis of time-series with smoother variations. It helps to retrieve oscillatory behavior of the data when the analysis is focused on amplitude and phase changes. The Morlet wavelet transform is not intended as a replacement for the Fourier transform, but rather a supplement to it that allows qualitative access to time-related changes which takes advantage of the multiple dimensions available in a free induction decay analysis. When a plane wave is modulated by a Gaussian function, a Morlet mother-wavelet is formed (for further detail see Domingues et al. 2005).

\section{Results and discussions}

\subsection{Seasonal climatology of ozone in the middle atmosphere}

The seasonal climatology of Ozone in the middle atmosphere is studied over the six sites (indicated in Fig. 1) in NH and $\mathrm{SH}$ including the hemispheric differences from 14 years of SABER/TIMED observations. Figure $2 \mathrm{a}-\mathrm{f}$ illustrate the monthly mean climatology of the six sites (hereafter) site- 1 $\left(50^{\circ} \mathrm{N}, 120^{\circ} \mathrm{W}\right)$, site- $3\left(50^{\circ} \mathrm{N}, 2.5^{\circ} \mathrm{E}\right)$ and site- $5\left(50^{\circ} \mathrm{N}\right.$, $\left.120^{\circ} \mathrm{E}\right)$ in the $\mathrm{NH}$ and site- $2\left(50^{\circ} \mathrm{S}, 120^{\circ} \mathrm{W}\right)$, site- $4\left(50^{\circ}\right.$ $\left.\mathrm{S}, 2.5^{\circ} \mathrm{E}\right)$ and site- $6\left(50^{\circ} \mathrm{S}, 120^{\circ} \mathrm{E}\right)$ in the $\mathrm{SH}$, respectively. The notable features observed from Fig. 2 is that the ozone peaks at two different altitudinal regions such as the stratosphere and mesosphere and lower thermosphere (MLT) region. This maximum ozone in the MLT region is also known as the secondary ozone maximum (Evans and Llewellyn 1972; Hays and Roble 1973; Miller and Ryder 1973). The night-time mixing ratio of ozone in the MLT is comparable to that found in the stratospheric maximum which is around $10 \mathrm{ppm}$ (Smith and Marsh 2005). In the MLT region the peak ozone occurs during March-May and September-December in both the hemispheres indicating a semi-annual oscillation in the MLT region. In contrast to
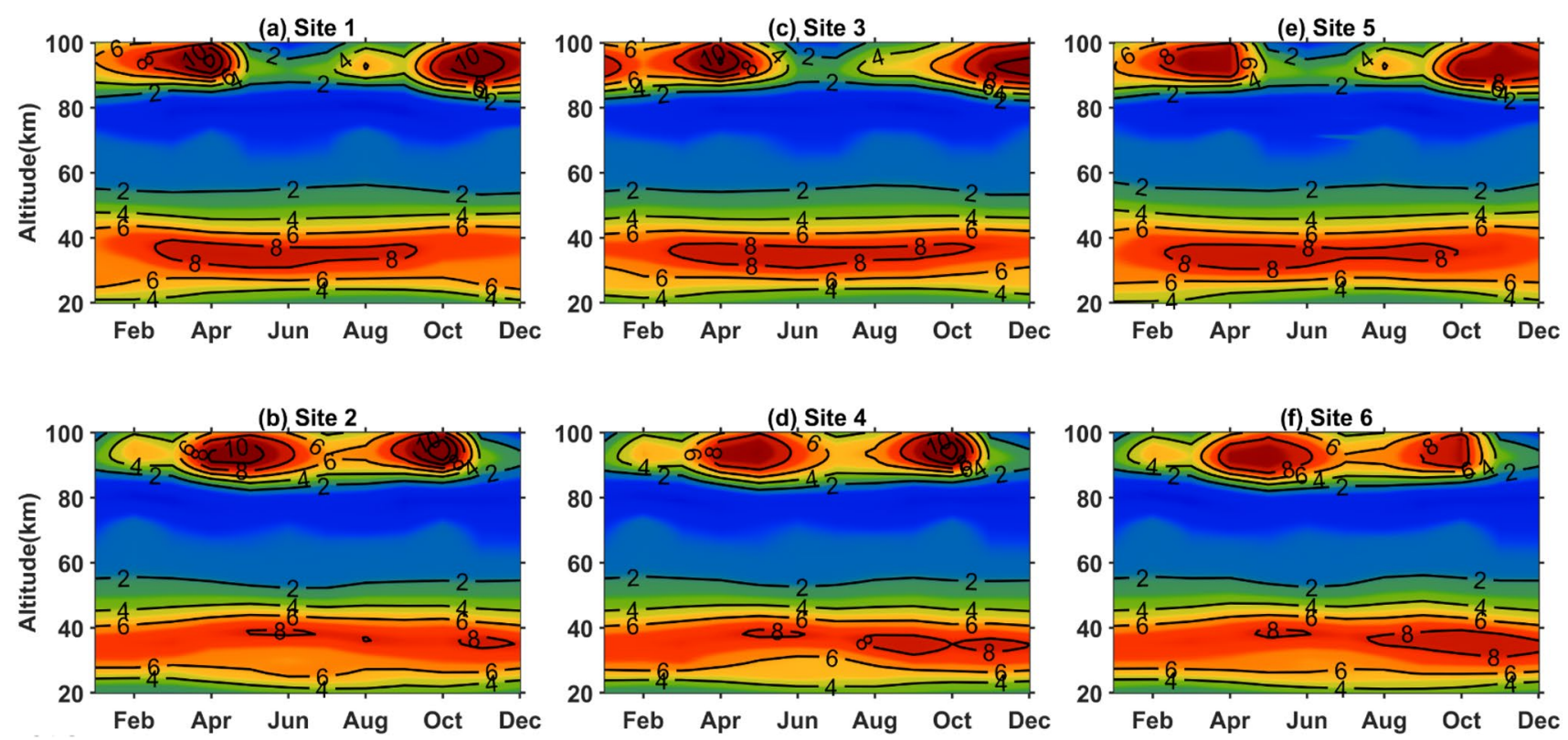

Fig. 2 Contour plots of climatological (2002-2015) ozone volume mixing ratio in parts per million (ppm) derived from SABER observations in the $\mathrm{NH}$ over a Site $1\left(50^{\circ} \mathrm{N}, 120^{\circ} \mathrm{W}\right)$, b Site $3\left(50^{\circ} \mathrm{N}, 2.5^{\circ}\right.$
E) and c Site $5\left(50^{\circ} \mathrm{N}, 120^{\circ} \mathrm{E}\right)$ and in the SH over d Site $2\left(50^{\circ} \mathrm{S}\right.$, $\left.120^{\circ} \mathrm{W}\right)$, e Site $4\left(50^{\circ} \mathrm{S}, 2.5^{\circ} \mathrm{E}\right)$ and $\mathbf{f}$ Site $6\left(50^{\circ} \mathrm{S}, 120^{\circ} \mathrm{E}\right)$ 
mesospheric ozone, the stratospheric ozone does not show such variability and is almost uniform with high magnitudes during summer relative to winter in both the hemispheres. Similar results were also noted from SAGE II satellite measurements of stratospheric ozone over the mid-latitudes as reported by Fioletov (2008). The studies of global distribution of stratospheric ozone derived from Nimbus 4 and 7 satellite also supports the observations indicated in Fig. 2 (Frederick et al. 1983; Maeda 1987). The magnitude of OMR is observed to be high as much as 8 ppmv in the stratospheric region (30-38 km) during winter-spring over all three sites of the $\mathrm{NH}$ and $\mathrm{SH}$.

The dynamical and photochemical processes control the ozone budget in the middle atmosphere (Langematz 2019; Reddy 1988). While the dynamical factors play a primary role in the enhancement of stratospheric ozone in both the hemispheres, whereas the radiative effects play secondary role. The mean poleward circulation of the subsiding air from the equator causes the build-up of ozone in the midlatitudes in both the hemispheres (Kulkarni 1962, 1968). Subsequently, this circulation is completed by returning towards equator at higher levels. Figure 2 also indicates high ozone mixing ratios with magnitudes of about $8 \mathrm{ppmv}$ in the mid-latitude sites in the stratospheric altitudes supporting the previous observational studies (e.g. Fioletov 2008 and references therein). The ozone builds from winter and peaks during the springtime and gradually decreases in summer to autumn transitional period. The eddy diffusion process is responsible for this ozone transport from low to high latitudes (Newell 1961). The selective eddy transport of ozone is basically indicating the northward moving air parcels contain more ozone than the southward moving air parcels. Figure 2 also indicates some interhemispheric differences in ozone mixing ratio in different seasons. For instance, the magnitudes of ozone in $\mathrm{SH}$ are less in late summer relative to the $\mathrm{NH}$. In contrast, during autumn and winter the magnitudes are more in SH than NH. This could be due to more destruction of ozone, specifically, through stratospheric intrusions into the troposphere in $\mathrm{NH}$ as compared to $\mathrm{SH}$ during wintertime (Kulkarni 1962, 1968). More quantifications about the seasonal differences are provided in section S1 (Supplementary material). It is noted that the magnitude of about $0.5 \mathrm{ppm}$ seasonal mean difference observed between both the hemispheres in stratospheric altitudes. These differences are expected due to the differences in solar input and local photochemistry in the stratosphere in both the hemispheres. Nevertheless, the seasonal mean differences are less significant for the summer and winter seasons.

Figure 2 indicates the mean picture, which does not reveal any interannual variations in the middle atmospheric ozone. Hence, the time series of monthly variation of ozone from Jan 2002 to Dec 2015 is shown in Fig. 3a-f over the NH and the SH sites, respectively. One can notice the large values of OMR, between 5 and $9 \mathrm{ppm}$, are observed at the stratosphere between 25 and $45 \mathrm{~km}$ and in the upper mesosphere between 85 and $100 \mathrm{~km}$. Figure 3 indicates that the stratospheric
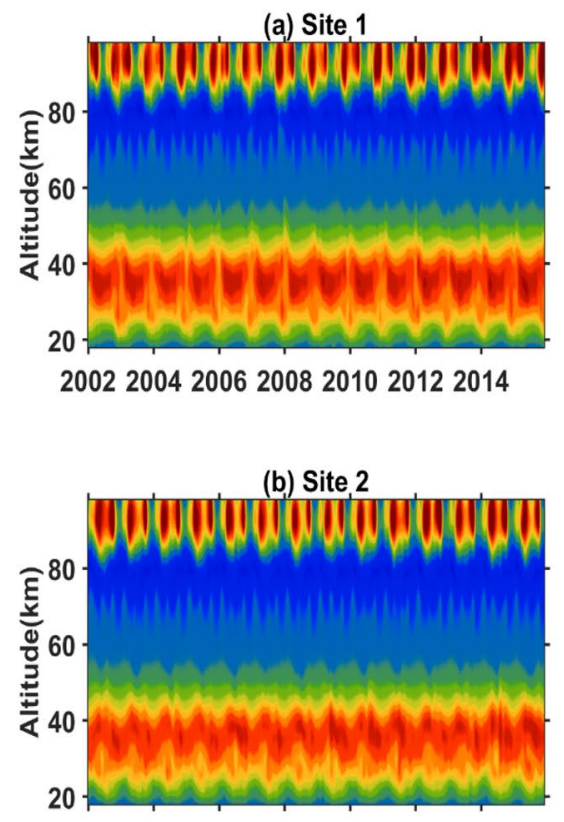

2002200420062008201020122014

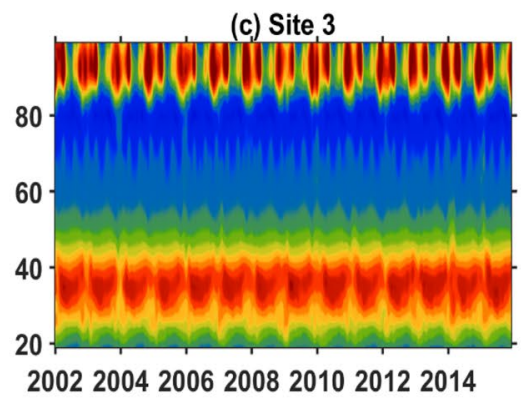

(d) Site 4

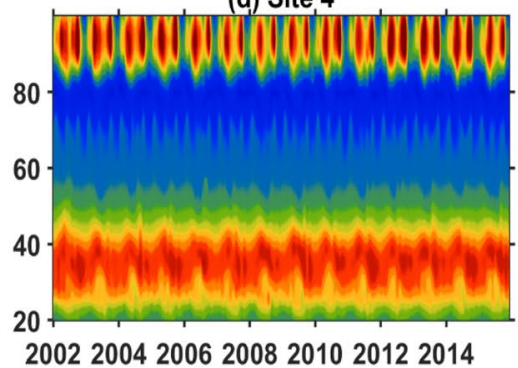

(e) Site 5

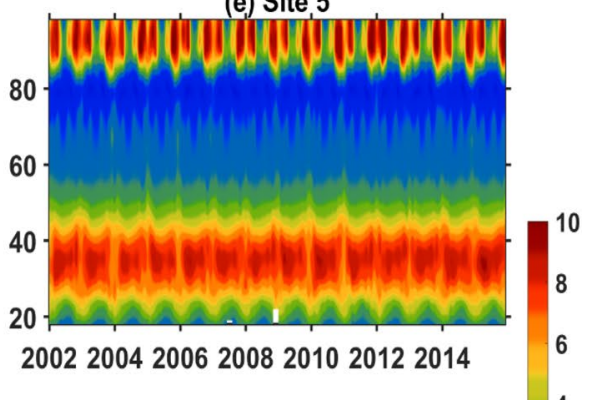

(f) Site 6

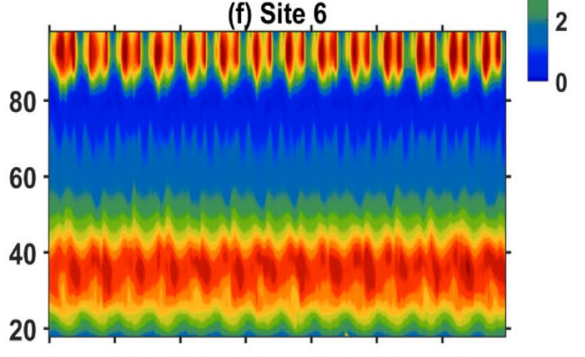

2002200420062008201020122014
Fig. 3 Contour plots of ozone volume mixing ratio in ppm (starting from January 2002 to December 2015) as derived from SABER observations in the $\mathrm{NH}$ over a Site $1\left(50^{\circ} \mathrm{N}, 120^{\circ} \mathrm{W}\right)$, b Site $3\left(50^{\circ}\right.$
$\left.\mathrm{N}, 2.5^{\circ} \mathrm{E}\right)$ and $\mathbf{c}$ Site $5\left(50^{\circ} \mathrm{N}, 120^{\circ} \mathrm{E}\right)$ and in the SH over d Site 2 $\left(50^{\circ} \mathrm{S}, 120^{\circ} \mathrm{W}\right)$, e Site $4\left(50^{\circ}, 2.5^{\circ} \mathrm{E}\right)$ and f Site $6\left(50^{\circ} \mathrm{S}, 120^{\circ} \mathrm{E}\right)$ 
ozone over the southern hemispheric sites is quite lesser than the northern hemispheric sites. This could be due to the seasonal variation of temperature is larger in the southern stratosphere than in the northern stratosphere, since the ozone density is inversely proportional to the temperature (Maeda 1987). The mesospheric and stratospheric ozone over the site- 1 (site-2) and site-3 (site-4) is slightly higher than site-5 (site-6) in both the $\mathrm{NH}$ (SH). More details on the longitudinal differences in the middle atmospheric ozone for both the hemispheres are shown in Figure S4 (section $\mathrm{S} 2$ in the supplementary material). It is observed that the differences are primarily noticed in the mesospheric region (Figure S4). Further, the prominent features observed from Fig. 3 are the oscillatory behaviors (lows and highs) in ozone in the stratospheric and mesospheric regions, which might correspond to the annual and semi-annual oscillations. Such types of results are also revealed by Nath and Sridharan (2014) over the tropical region. More details on the characteristics of the observed oscillations are discussed in the following sections.
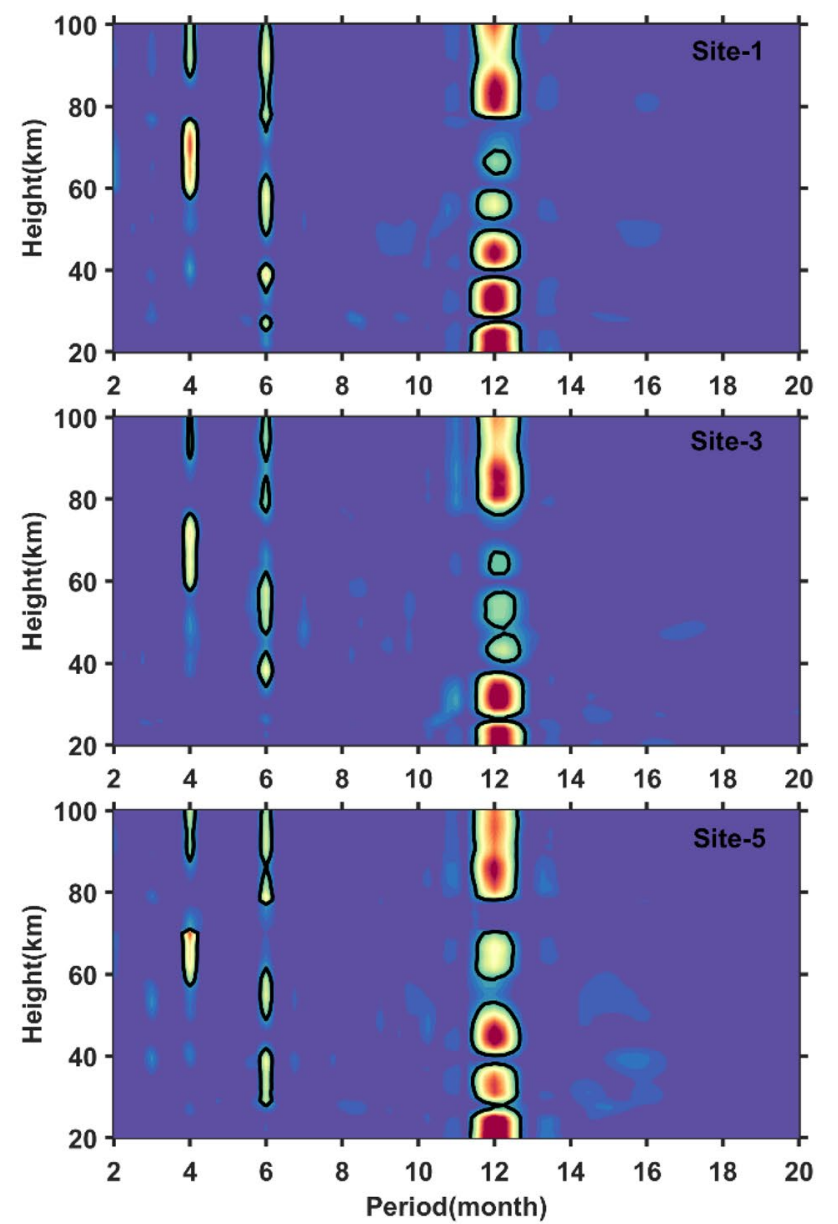

\subsection{Characteristics of the atmospheric oscillations}

Figure 3 described in the previous section indicate some important oscillations in the middle atmospheric ozone measurements from SABER/TIMED satellite. In order to reveal the characteristics of these oscillations, we have performed spectral analysis using two techniques: LSP and Wavelet transform. Both sophisticated numerical methods are increasingly used and are well-adapted for analysis and characterization of atmospheric oscillations. For example, Sharma et al. (2017) used LSP and wavelet techniques to study seasonal oscillations over Mt. Abu (in NH) and Reunion Island (in $\mathrm{SH}$ ) from SABER temperature time-series. Previously, Sivakumar et al. (2011) used the same LSP method to study and characterize seasonal variability from temperature Lidar profiles recorded at Reunion Island. Figure 4 indicates the outcome of LSP analysis for the Northern and Southern Hemispheres over the selected sites using the 14 years (January 2002-December 2015) of SABER/ TIMED satellite observations. For instance, Fig. 4 (left
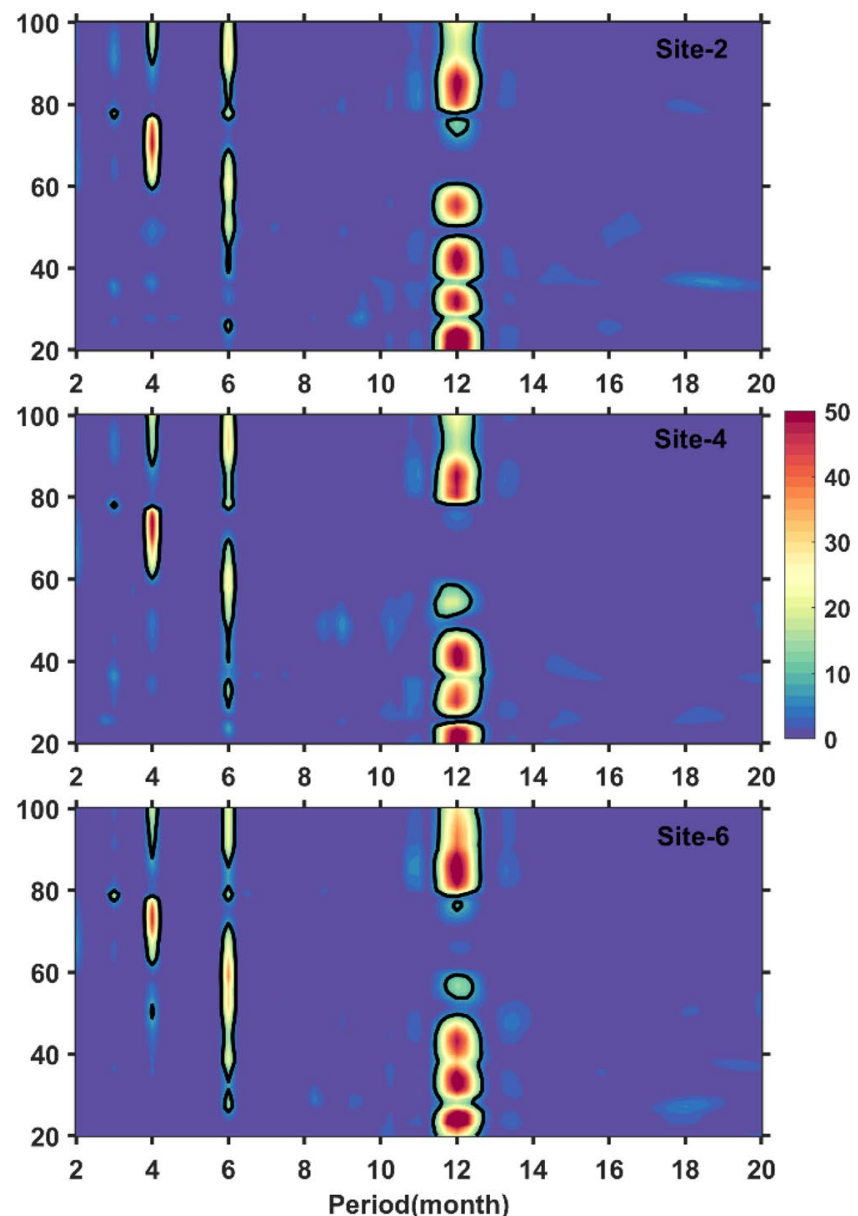

Fig. 4 Lomb-Scargle periodogram of the ozone over all six sites of the northern hemisphere (left panel) and the southern hemisphere (right panel) 
panel) indicates the vertical structure of the various atmospheric oscillations observed in the NH for the site- 1 , site- 3 and site-5, respectively and Fig. 4 (right panel) for the $\mathrm{SH}$ (site-2, site-4 and site-6). The contours (thick solid lines) indicate the amplitude that is significant at $95 \%$ confidence level. The dominant oscillation observed is the AO that is strongly present in the middle atmosphere over the $\mathrm{NH}$ and $\mathrm{SH}$. In particular, the stratosphere and upper mesosphere indicate the significant amplitudes of AO. The other important oscillation is the SAO, which is also found throughout the middle atmosphere. The peak amplitudes of the SAO can be found in 40-60 km and 80-100 km for all the sites in the $\mathrm{NH}$ and $\mathrm{SH}$. In the $\mathrm{NH}$, magnitude of the SAO is little weaker compared to the SH SSAO. In addition to that we have also found another interesting oscillation that peaks at 4-months in the middle atmospheric ozone variations. The 4-month oscillation prominently seen in 60-80 km altitude and in the upper mesosphere region. The amplitude of the 4-month oscillations is quite stronger in the $\mathrm{SH}$ than $\mathrm{NH}$.

The spectral analysis shown in Fig. 4 provides the prominent oscillations in a given time series, but it does not reveal the temporal evolution (inter-annual and intra-seasonal variations) of the observed frequencies. Therefore, the Morlet wavelet analysis is used to divulge the temporal variations of the prominent frequencies in the stratosphere and mesosphere region. Figures 5 and 6 give the most important information about atmospheric oscillations using wavelet analysis of the time series of stratospheric $(30-35 \mathrm{~km})$ and mesospheric (90-100 km) ozone over the Northern and the Southern Hemispheric sites. Figure 5 (top panel) shows that in the stratosphere region at sites 1,3 and 5 shows significant $\mathrm{AO}$ with some interannual variations. The temporal evolution of AO is slightly different for the site- 3 relative to the site- 1 and site-5. It is also noted a significant interannual variation in the stratospheric SAO (SSAO). The SSAO is quite strong during epochs: 2004-2006 and 2008-2011 and 2013-2014 in site- 1 and site-5. Hence, site- 1 and site- 5 show similar behaviors in the evolution of prominent oscillations except site- 3 in the NH SSAO. The AO appears to be very strong oscillation in the mesospheric altitudes with no significant interannual variations. Similarly, the mesospheric SAO (MSAO) is also seen from Fig. 5b but it is not significant at 95\% confidence level over all the selected sites in the $\mathrm{NH}$.

Figure 6 indicates the wavelet analysis of the time series of stratospheric and mesospheric ozone over the SH. Figure 6 a shows the AO observed to be significant oscillation similar to the NH. While the SSAO and its interannual variations are quite noteworthy in $\mathrm{SH}$ (site-4) relative to $\mathrm{NH}$ (site-3). Similar to the NH sites, the mesospheric AO is very strong and significant. The MSAO is also a notable feature in the wavelet analysis of southern hemispheric ozone variability in all the sites and is much significant over the site 2 and site 4 . The interannual variation of MSAO is either a manifestation of some unknown ozone photochemical mechanism, or it could be driven by a seasonal variation in the vertical transport of atomic oxygen from the thermosphere (Bevilacqua et al. 1990). Hence, the stratospheric and mesospheric ozone variations show two prominent oscillations such as the AO and SAO in both the hemispheres with some differences noted in their interannual variability. Moreover,
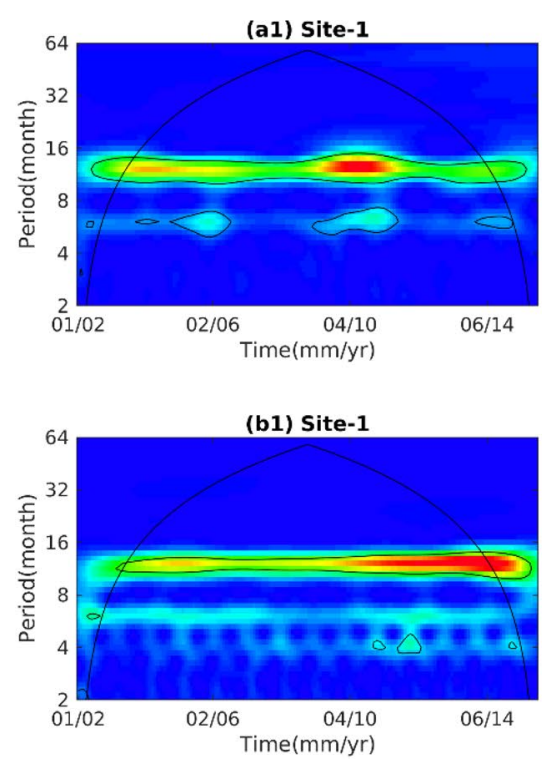

(a) Stratosphere

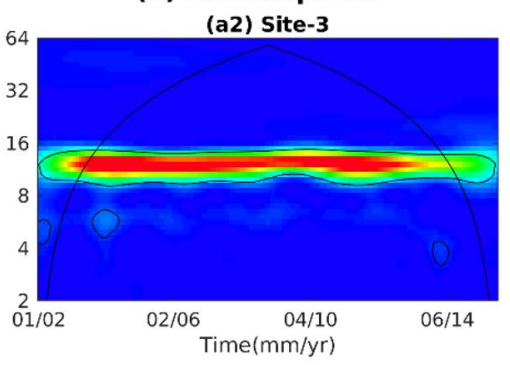

(b) Mesosphere

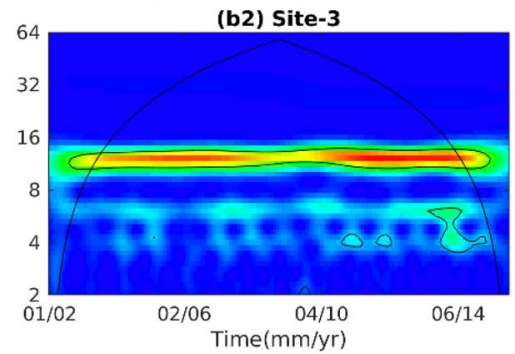

(a3) Site-5

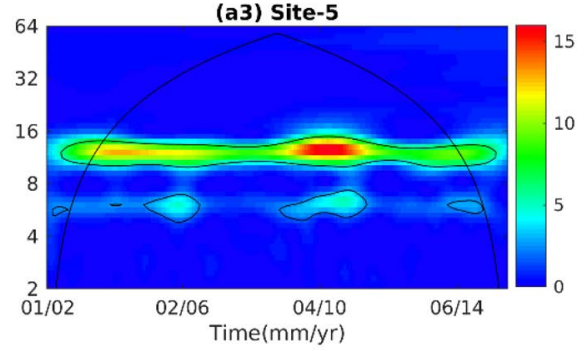

(b3) Site-5

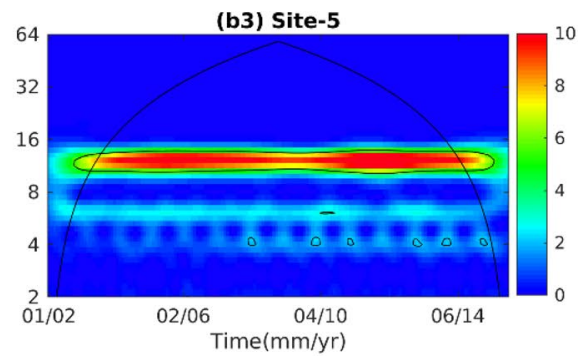

Fig. 5 The wavelet power spectrum of ozone mixing ratio for site-1, site-3 and site-5 in the (a1-a3) stratosphere and (b1-b3) in the mesosphere altitudes $(90-100 \mathrm{~km})$ over $\mathrm{NH}$ 
(a) Stratosphere

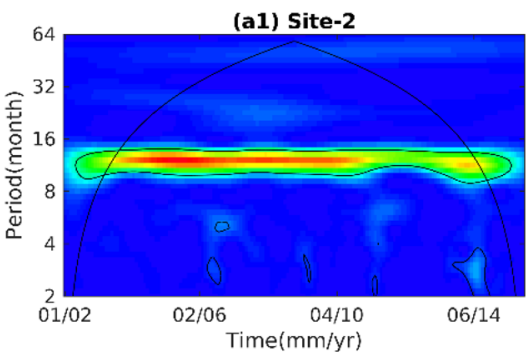

(b1) Site-2

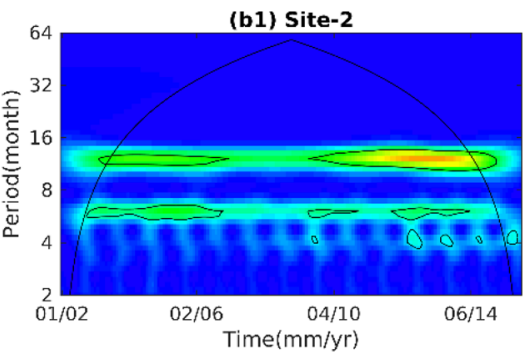

(a2) Site-4

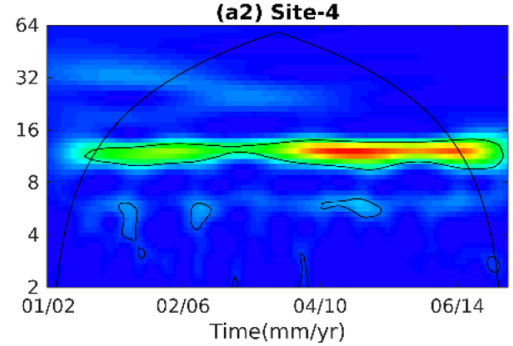

(b) Mesosphere

(b2) Site-4

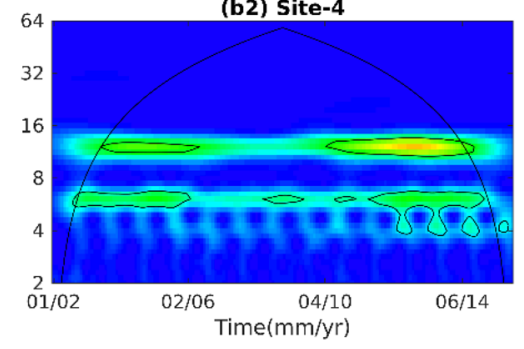

(a3) Site-6

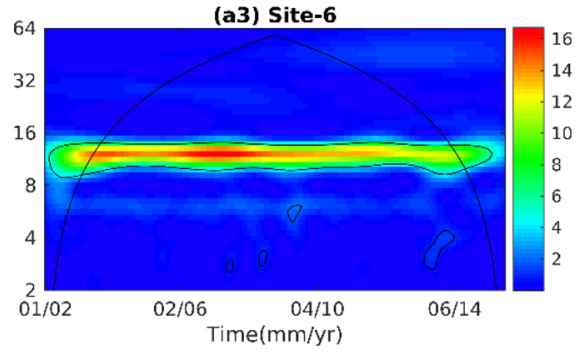

(b3) Site-6

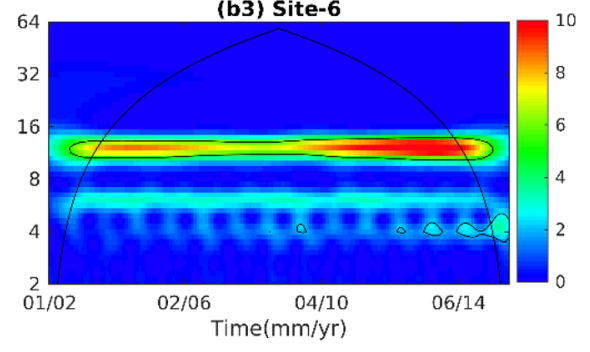

Fig. 6 Same as Fig. 5 but for SH

there are some longitudinal differences noted in the temporal evolution of two dominant oscillations (AO and SAO) for different sites in both the hemispheres. Therefore, we discuss these longitudinal asymmetries by comparing with the mean zonal spectrum of middle atmospheric ozone from SABER/ TIMED observations.

\subsection{Atmospheric oscillations of zonal mean ozone}

In this section, we did the spectral analysis of the zonal mean ozone, in order to understand the longitudinal asymmetry in the atmospheric oscillations over both the hemispheres. Figure 7a, b shows LSP of zonal mean ozone over the northern and the southern hemispheres, respectively. In Fig. 7, AO is found to be significant over both the hemispheres in the middle atmosphere. However, the strongest magnitudes of $\mathrm{AO}$ are noted in the $\mathrm{SH}$ that $\mathrm{NH}$. Furthermore, the SAO is quite strong in the southern hemisphere than the northern hemisphere. Nevertheless, $\mathrm{SAO}$ in $\mathrm{NH}$ is significant in the upper mesosphere. It is also interesting to note that the zonal mean spectrum of AO, though significant, but amplitudes are less than the individual sites (Fig. 4, left panel). While the difference in the amplitudes of AO in the zonal mean spectrum (Fig. 7b) and individual sites (Fig. 4, right panel) is very less in the southern hemisphere. This signifies that the longitudinal asymmetry in the northern hemisphere is prominent than the southern hemisphere. The reason for this longitudinal asymmetry could be due to the differences in the propagating planetary waves that modulate the ozone in the middle atmosphere. It is obvious that the planetary wave energy is quite strong in the northern hemisphere in the presence of the elevated topographies and land-ocean thermal contrast that generate these large-scale waves.

It is also interesting to note the 4-month oscillation, in addition to the dominant $\mathrm{AO}$ and $\mathrm{SAO}$, in the middle atmospheric ozone variability, but it is weakly significant. Figure 7 indicates that this oscillation is present prominently in the upper mesosphere over both the hemispheres. However, the 4-month oscillation is dominantly seen in the middle atmosphere between 60 and $80 \mathrm{~km}$, at the individual sites (Fig. 4).

We have further analysed the vertical structure of this 4-month oscillation. Figure 8 indicates the vertical profiles of the amplitude of 4-month oscillation in zonal mean and different sites shown in Fig. 1. The amplitude of this oscillation is very strong between 60 and $80 \mathrm{~km}$ at different sites but is very weak in zonal mean spectrum. This indicates that there is longitudinal asymmetry similar to other dominant oscillations in the middle atmosphere. This is more clearly seen in the zonal mean spectrum over the northern hemisphere (Fig. 8a). In order to explore more about the 4-month oscillation, we also performed the wavelet analysis on the ozone mixing ratio between 60 and $80 \mathrm{~km}$ at different sites in $\mathrm{NH}$ and $\mathrm{SH}$. The wavelet power spectrum is shown in Fig. 9 indicates significant power $\sim 4$-months in the mesospheric altitudes. While the amplitude of SAO and AO are less significant except AO which is significant over site-5. The source mechanism for the 4-month oscillation is intriguing as no reports so far studied such oscillation in the middle atmosphere as per the author's knowledge. However, the non-linear interaction between the SAO and AO can yield the 4-month oscillation in the middle atmosphere. Nevertheless, more detailed study is required for understanding the 
Fig. 7 Lomb-Scargle Periodogram of zonal mean ozone over a the northern hemisphere and $\mathbf{b}$ the southern hemisphere

Fig. 8 Height-Amplitude line plot of four-monthly oscillation for a the NH sites and zonal mean $\mathbf{b}$ the SH sites and zonal mean (a) Northern Hemisphere

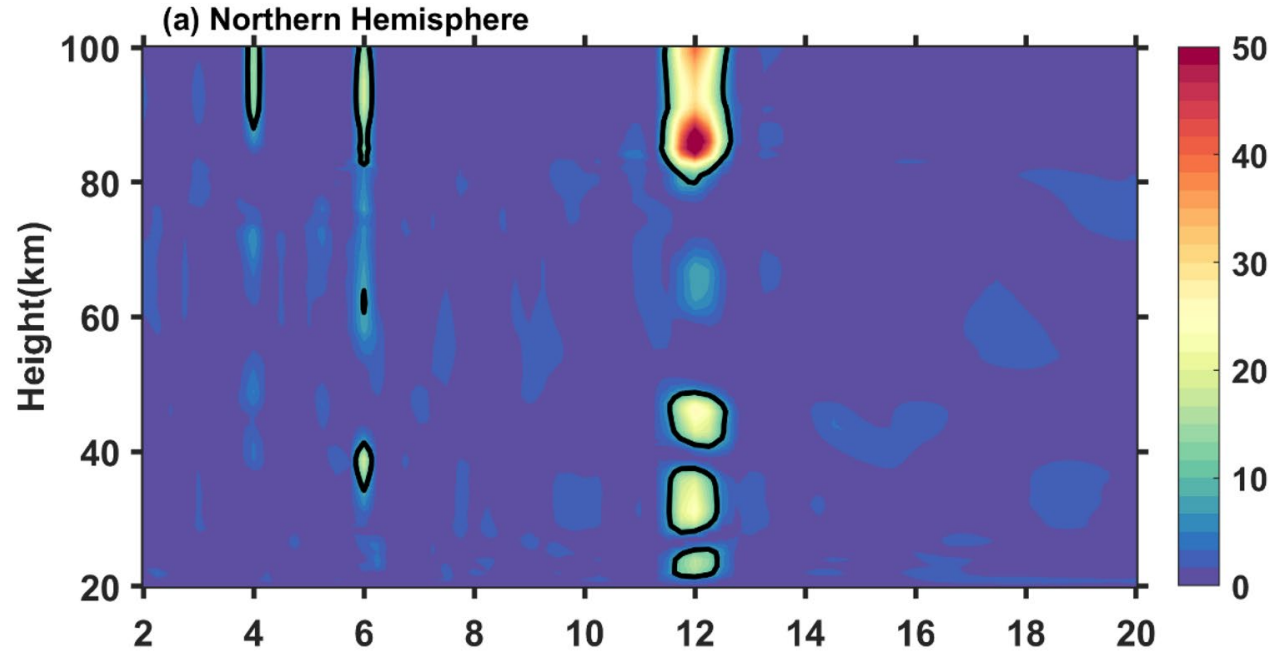

(b) Southern Hemisphere
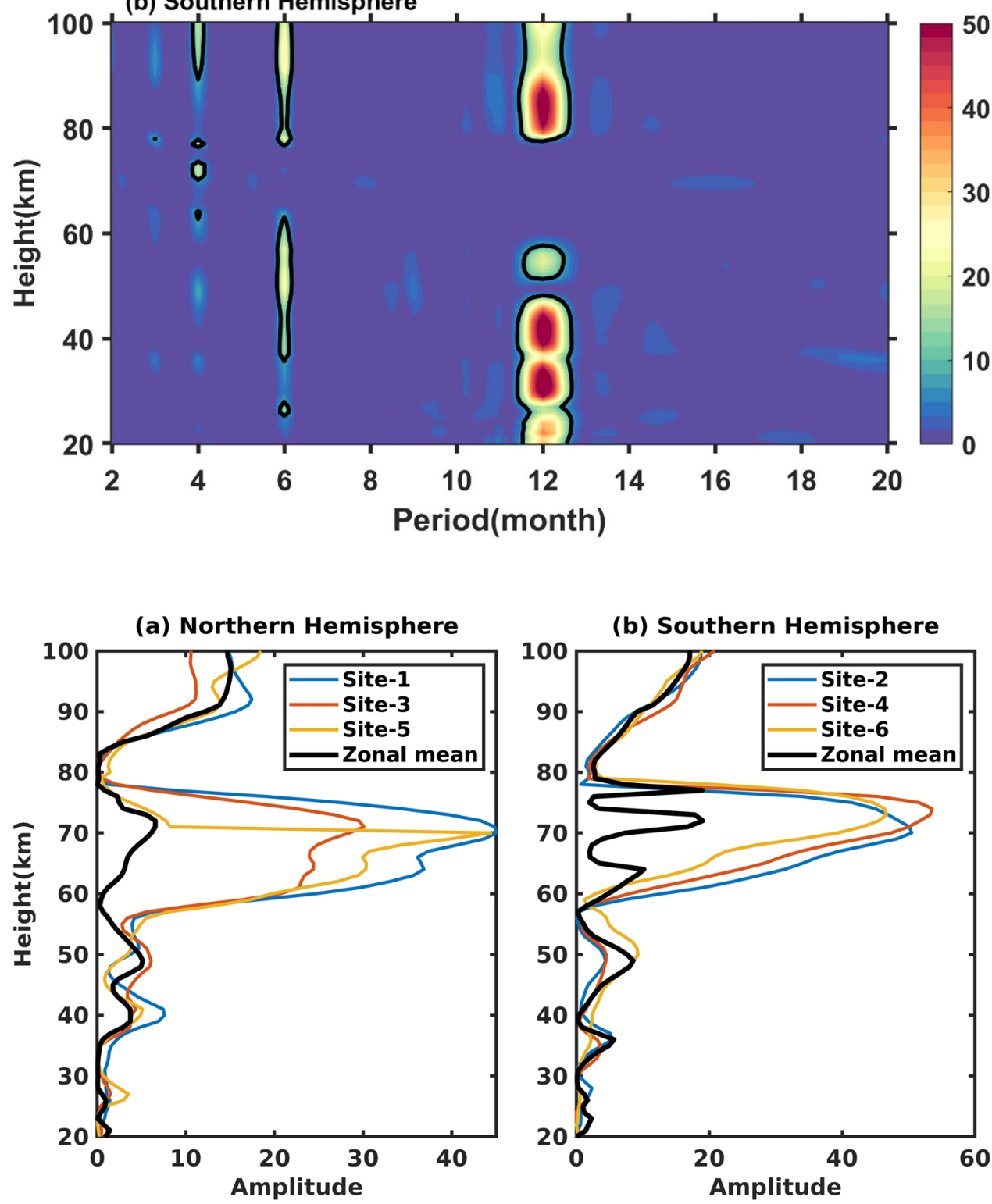

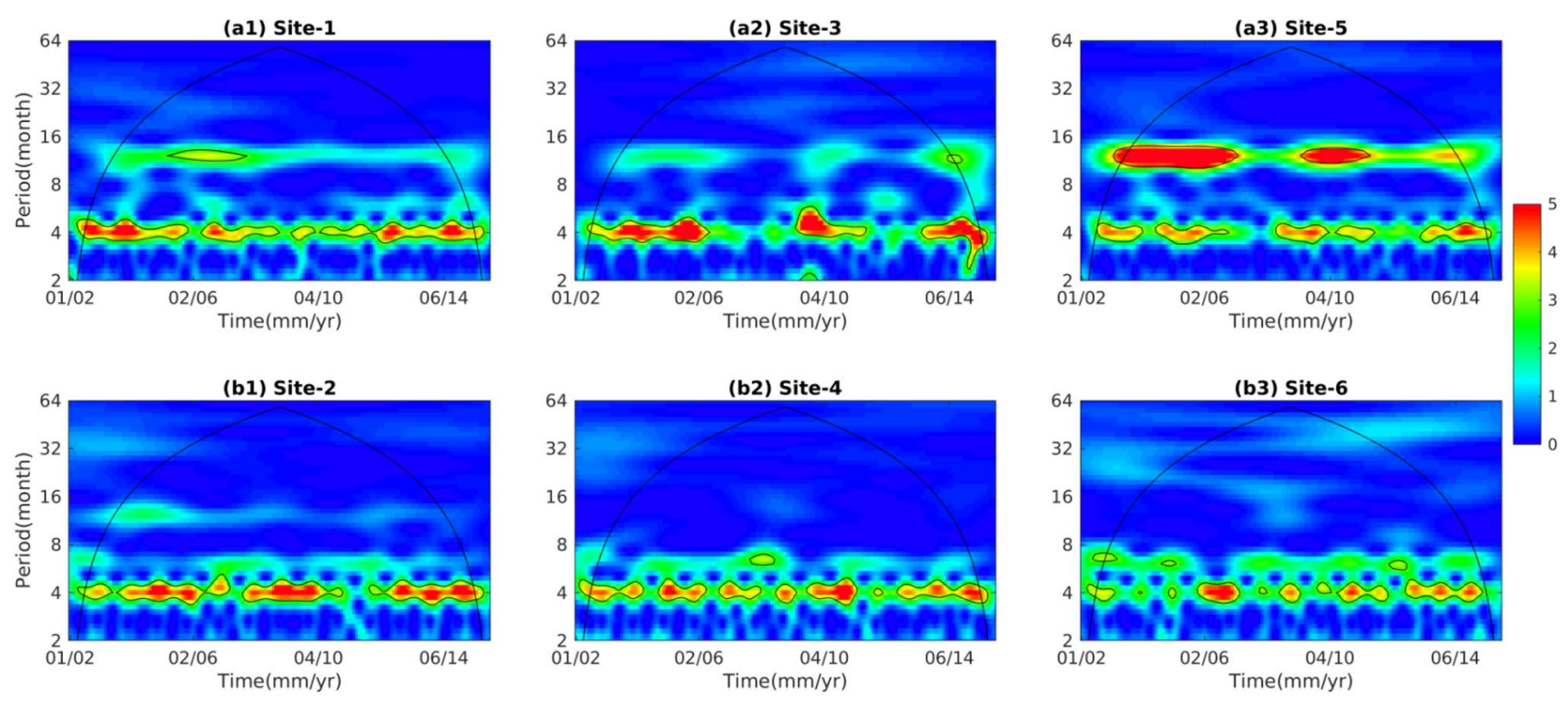

Fig. 9 Wavelet power spectrum of ozone mixing ratio anomalies between 60 and $80 \mathrm{~km}$ for Northern Hemispheric sites (upper panel): a1 site-1, $\mathbf{a} 2$ site- 3 and $\mathbf{a} 3$ site- 5 and for Southern Hemispheric sites (lower panel): b1 site-2, b2 site- 4 and b3 site-6
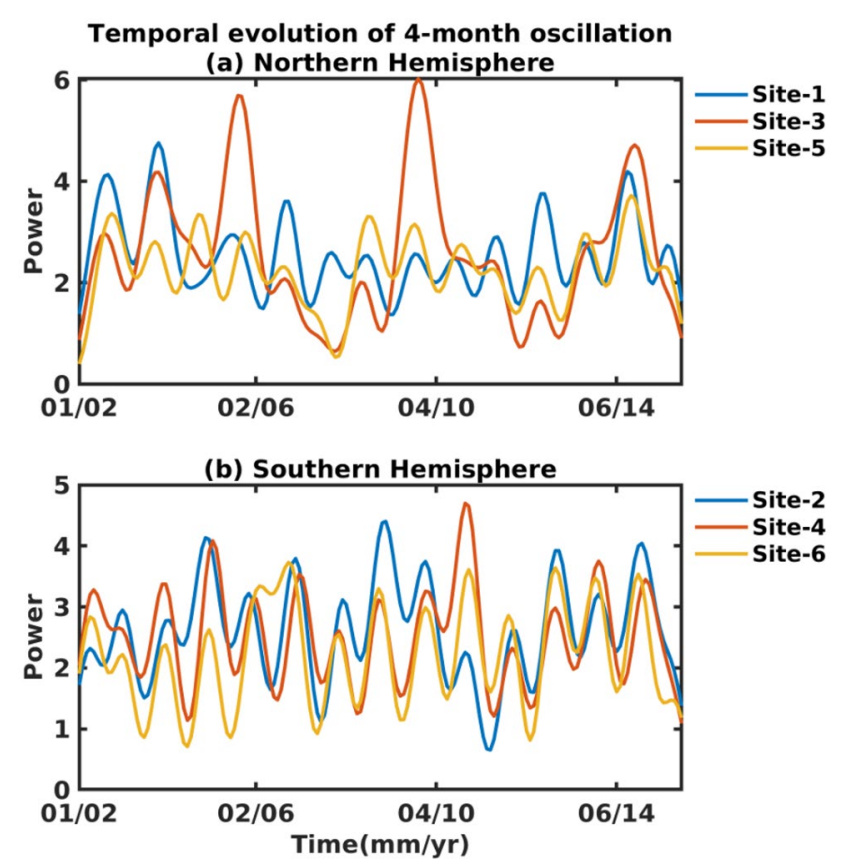

Fig. 10 Temporal evolution of the amplitudes of the 4-month oscillation at different sites in $\mathbf{a}$ Northern and $\mathbf{b}$ Southern hemispheres

origin of this oscillation. Figure 9 also indicates the substantial interannual variability in the 4-month oscillation. To further explore the temporal evolution, we plotted the time series of the 4-month oscillation in Fig. 10 which is retrieved from the wavelet analysis (Fig. 9). The NH sites (Fig. 10a) shows the significant differences in the magnitude and phase of 4-month oscillation. This is expected as the vertically propagating waves (small-scale to planetaryscale) significantly modulates the longer-period oscillations. In contrast, the $\mathrm{SH}$ sites show no such differences in the magnitude and phase of the 4-month oscillation. However, the 4-month oscillation also indicates the significant interannual variations in the $\mathrm{SH}$. A more detailed investigation of this 4-month oscillation is further required to understand the impact on the general circulation of the middle atmosphere.

\section{Summary}

The middle atmospheric ozone plays a key role in the Earth's atmosphere by shielding the Earth's surface from harmful ultraviolet radiation. There are many factors affect middle atmospheric ozone (such as chemical reactions, zonal and meridional transports and solar variability) and hence it is imperative to understand the seasonal and inter-annual variability in ozone. Therefore, we have studied the characteristics of middle atmospheric ozone using the 14 years (2002-2015) of observations from the SABER instrument onboard TIMED satellite, over NH and SH latitudes. It is noted that there is seasonal variability in the middle atmosphere, specifically over the stratosphere and mesosphere regions, with higher magnitudes of stratospheric ozone in summer season in both the hemispheres. However, there are no significant interhemispheric differences in the magnitudes summer ozone in the stratosphere.

The temporal evolution of the middle atmospheric ozone indicates the prominent oscillatory behaviors in ozone, which corresponds to the annual and semi-annual 
oscillations. The characteristics of these oscillations are studied using spectral analysis such as LSP and Wavelet transform. From the LSP analysis, the dominant oscillation noted in the middle atmospheric ozone is the AO with significant amplitudes over both the hemispheres. Significant SAO is also found in $40-60 \mathrm{~km}$ and $80-100 \mathrm{~km}$ for all the sites in the $\mathrm{NH}$ and $\mathrm{SH}$. Moreover, we have also found another oscillation that peaks at 4-months and has prominently seen in $60-80 \mathrm{~km}$ altitudes and in the upper mesosphere region over both the hemispheres. The amplitude of the 4-month oscillations is quite stronger in the SH than NH. The temporal evaluation (inter-annual and intra-seasonal variations) of the observed frequencies is studied using the Morlet wavelet analysis. The strength of the AO is relatively higher than $\mathrm{SAO}$ in both the hemispheric sites, however, the interannual variability of SAO is stronger than the AO.

There are some longitudinal differences noted in the temporal evolution of $\mathrm{AO}$ and SAO for different sites in both the hemispheres. Therefore, we discussed these longitudinal asymmetries by comparing them with the mean zonal spectrum of middle atmospheric ozone. LSP of zonal mean ozone shows significant $\mathrm{AO}$ over both the hemispheres, with stronger magnitudes in $\mathrm{SH}$ than $\mathrm{NH}$ in the middle atmosphere. Similar to AO the SAO is also quite strong in the southern hemisphere than northern hemisphere. Hence, the comparison of the LSP spectrum of zonal mean and individual sites reveals the longitudinal asymmetry in the northern hemisphere is prominent. It is also interesting to note the 4-month oscillation which is dominantly seen in the middle atmosphere between 60 and $80 \mathrm{~km}$ altitude region, at the individual sites so we have further analysed the temporal and vertical structure of this 4-month oscillation. The longitudinal asymmetry of this 4-month oscillations is quite stronger in both the hemispheres. While the origin of this oscillation in the middle atmosphere could be associated with the nonlinear interaction of the $\mathrm{AO}$ and SAO. Nevertheless, a more detailed study is further required to understand the possible sources of the 4-month oscillation and its influence on the middle atmospheric dynamics.

Acknowledgements Authors are thankful to SABER onboard TIMED satellite team members for providing valuable ozone data (https://saber .gats-inc.com/). This work is supported by the Dept. of Space, Govt. of India.

\section{References}

Allen M, Lunine JI, Yung YL (1984) The vertical distribution of ozone in the mesosphere and lower thermosphere. J Geophys Res 89:4841. https://doi.org/10.1029/JD089iD03p04841

Beig G, Fadnavis S, Schmidt H, Brasseur GP (2012) Inter-comparison of 11-year solar cycle response in mesospheric ozone and temperature obtained by HALOE satellite data and HAMMONIA model. J Geophys Res Atmos. https://doi.org/10.1029/2011JD015697
Bevilacqua RM, Strobel DF, Summers ME et al (1990) The seasonal variation of water vapor and ozone in the upper mesosphere: implications for vertical transport and ozone photochemistry. J Geophys Res 95:883. https://doi.org/10.1029/JD095iD01p00883

Brasseur G, Hitchman MH (1988) Stratospheric response to trace gas perturbations: changes in ozone and temperature distributions. Science (New York, NY) 240:634-637. https://doi.org/10.1126/ science. 240.4852 .634

Cicerone RJ (1987) Changes in stratospheric ozone. Science (New York, NY) 237:35-42. https://doi.org/10.1126/scien ce.237.4810.35

Domingues MO, Mendes O, da Costa AM (2005) On wavelet techniques in atmospheric sciences. Adv Space Res 35:831-842. https ://doi.org/10.1016/J.ASR.2005.02.097

Evans WFJ, Llewellyn EJ (1972) Measurements of mesospheric ozone from observations of the $1.27 \mu$ band. Radio Sci 7:45-50

Fioletov VE (2008) Ozone climatology, trends, and substances that control ozone. Atmos Ocean 46(1):39-67. https://doi.org/10.3137/ ao. 460103

Fioletov VE, Shepherd TG (2003) Seasonal persistence of midlatitude total ozone anomalies. Geophys Res Lett. https://doi. org/10.1029/2002GL016739

Frederick JE, Huang FT, Douglass AR, Reber CA (1983) The distribution and annual cycle of ozone in the upper stratosphere. $\mathrm{J}$ Geophys Res 88:3819. https://doi.org/10.1029/JC088iC06p03819

Garcia RR, Solomon S (1994) A new numerical model of the middle atmosphere: 2 Ozone and related species. J Geophys Res 99:12937. https://doi.org/10.1029/94JD00725

Hays PB, Roble RG (1973) Observation of mesospheric ozone at low latitudes. Planet Space Sci 21:273-279

Hingane LS (1984) Ozone in the mesosphere and lower thermosphere. J Earth Syst Sci 93:91-103. https://doi.org/10.1007/BF02871988

Huang FT, Mayr HG, Russell JM III, Mlynczak MG (2016) Ozone and temperature decadal responses to solar variability in the mesosphere and lower thermosphere, based on measurements from SABER on TIMED. Ann Geophys 34:29-40. https://doi. org/10.5194/angeo-34-29-2016

Katsavrias C, Preka-Papadema P, Moussas X (2012) Wavelet analysis on solar wind parameters and geomagnetic indices. Sol Phys 280:623-640. https://doi.org/10.1007/s11207-012-0078-6

Kulkarni RN (1962) Comparison of ozone variations and of its distribution with height over middle latitudes of the two hemispheres. Quart J R Meteorol Soc. https://doi.org/10.1002/qj.49708837813

Kulkarni RN (1968) Ozone fluctuations in relation to upper air perturbations in the middle latitudes of the southern hemisphere. Tellus 20(2):305-313. https://doi.org/10.3402/tellusa.v20i2.10010

Langematz U (2019) Stratospheric ozone: down and up through the anthropocene. ChemTexts 5:8. https://doi.org/10.1007/s4082 8-019-0082-7

Maeda K (1987) Annual and semiannual oscillations of stratospheric ozone. Pure Appl Geophys PAGEOPH 125:147-165. https://doi. org/10.1007/BF00878619

Marsh DR, Skinner WR, Marshall AR et al (2002) High Resolution Doppler Imager observations of ozone in the mesosphere and lower thermosphere. J Geophys Res 107:4390. https://doi. org/10.1029/2001JD001505

Miller DE, Ryder P (1973) Measurement of the ozone concentration from 55 to $95 \mathrm{~km}$ at sunset. Planet Space Sci 21:963-970

Morlet J, Arens G, Fourgeau E, Glard D (1982) Wave propagation and sampling theory-Part I: complex signal and scattering in multilayered media. Geophysics 47:203-221. https://doi. org/10.1190/1.1441328

Mze N, Hauchecorne A, Bencherif H et al (2010) Climatology and comparison of ozone from ENVISAT/GOMOS and SHADOZ/ balloon-sonde observations in the southern tropics. Atmos Chem Phys 10:8025-8035. https://doi.org/10.5194/acp-10-8025-2010 
Nagahama T, Nakane H, Fujinuma Y et al (1999) Ground-based millimeter-wave observations of ozone in the upper stratosphere and mesosphere over Tsukuba. Earth Planets Space 51:1287-1296. https://doi.org/10.1186/BF03351602

Nath O, Sridharan S (2014) Long-term variabilities and tendencies in zonal mean TIMED-SABER ozone and temperature in the middle atmosphere at $10-15^{\circ} \mathrm{N}$. J Atmos Solar Terr Phys 120:1-8. https ://doi.org/10.1016/J.JASTP.2014.08.010

Newell RE (1961) The transport of trace substances in the atmosphere and their implications for the general circulation of the stratosphere. Geofisica Pura e Applicata 49:137. https://doi. org/10.1007/BF01992149

Perliski LM, London J (1989) Satellite observed long-term averaged seasonal and spatial ozone variations in the stratosphere. Planet Space Sci 37:1509-1525. https://doi.org/10.1016/00320633(89)90142-6

Perliski LM, Solomon S, London J (1989) On the interpretation of seasonal variations of stratospheric ozone. Planet Space Sci 37:1527-1538. https://doi.org/10.1016/0032-0633(89)90143-8

Portmann RW, Daniel JS, Ravishankara AR (2012) Stratospheric ozone depletion due to nitrous oxide: influences of other gases. Philos Trans R Soc B Biol Sci 367:1256-1264. https://doi.org/10.1098/ rstb.2011.0377

Reddy CA (1988) The middle atmosphere: processes and Interactions. Ind J Radio Space Phys 17:193-202

Remsberg E, Lingenfelser G (2010) Analysis of SAGE II ozone of the middle and upper stratosphere for its response to a decadalscale forcing. Atmos Chem Phys 10:11779-11790. https://doi. org/10.5194/acp-10-11779-2010

Rieder HE, Frossard L, Ribatet M et al (2013) On the relationship between total ozone and atmospheric dynamics and chemistry at mid-latitudes-Part 2: the effects of the El Niño/Southern Oscillation, volcanic eruptions and contributions of atmospheric dynamics and chemistry to long-term total ozone. Atmos Chem Phys 13:165-179. https://doi.org/10.5194/acp-13-165-2013

Russell JMIII, Mlynczak MG, Gordley LL, Tansock J, Esplin R (1999) An overview of the SABER experiment and preliminary calibration results. Proc SPIE Int Soc Opt Eng 3756:277-288

Schneider N, Selsis F, Urban J et al (2005) Seasonal and diurnal ozone variations: observations and modeling. J Atmos Chem 50:25-47. https://doi.org/10.1007/s10874-005-1172-z
Sharma S, Kumar P, Jethva C et al (2017) Investigations of the middle atmospheric thermal structure and oscillations over sub-tropical regions in the Northern and Southern Hemispheres. Clim Dyn 48:3671-3684. https://doi.org/10.1007/s00382-016-3293-2

Sivakumar V, Portafaix T, Bencherif $\mathrm{H}$ et al (2007) Stratospheric ozone climatology and variability over a southern subtropical site: Reunion Island $\left(21^{\circ} \mathrm{S} ; 55^{\circ} \mathrm{E}\right)$. Ann Geophys 25:2321-2334. https:// doi.org/10.5194/angeo-25-2321-2007

Sivakumar V, Vishnu Prasanth P, Kishore P et al (2011) Rayleigh LIDAR and satellite (HALOE, SABER, CHAMP and COSMIC) measurements of stratosphere-mesosphere temperature over a southern sub-tropical site, Reunion $\left(20.8^{\circ} \mathrm{S} ; 55.5^{\circ} \mathrm{E}\right)$ : climatology and comparison study. Ann Geophys 29:649-662. https://doi. org/10.5194/angeo-29-649-2011

Smith AK, Marsh DR (2005) Processes that account for the ozone maximum at the mesopause. J Geophys Res 110:D23305. https:// doi.org/10.1029/2005JD006298

Solomon S, Portmann RW, Garcia RR et al (1996) The role of aerosol variations in anthropogenic ozone depletion at northern midlatitudes. J Geophys Res Atmos 101:6713-6727. https://doi. org/10.1029/95JD03353

Solomon S, Portmann RW, Garcia RR et al (1998) Ozone depletion at mid-latitudes: coupling of volcanic aerosols and temperature variability to anthropogenic chlorine. Geophys Res Lett 25:18711874. https://doi.org/10.1029/98GL01293

Steinbrecht W, Claude H, Winkler P (2004) Enhanced upper stratospheric ozone: sign of recovery or solar cycle effect? J Geophys Res 109:D02308. https://doi.org/10.1029/2003JD004284

Thomas RJ (1990) Seasonal ozone variations in the upper mesosphere. J Geophys Res 95:7395. https://doi.org/10.1029/JD095iD06p 07395

Zechmeister M, Kürster M (2009) The generalised Lomb-Scargle periodogram - a new formalism for the floating-mean and Keplerian periodograms. Astron Astrophys. https://doi.org/10.1051/00046361:200811296 